\title{
Architecture for humanity: sharing the experience of MERCY Malaysia Core House Project in Banda Aceh, Indonesia
}

\author{
S. S. Zubir, H. Amirrol \& N. A. Samah \\ Faculty of Architecture, Planning \& Surveying, \\ Universiti Teknologi MARA, Malaysia
}

\begin{abstract}
The 26 December 2004 tsunami that devastated many coastal regions of the Indian Ocean has prompted many Government and Non-Government Agencies to look into alternative ways in responding to emergency relief efforts. One way is to adopt traditional methods of construction in order to generate an affordable and sustainable built-environment. The intent of this paper is to delineate the learning experiences from MERCY Malaysia Core Project in providing shelter for the Internally Displaced Persons (IDP) affected by the disaster. This paper focuses on three issues that MERCY took into consideration in formulating a workable praxis to the problems of mass housing in the disaster area. The first was by critically examining the social, cultural and economic factors that were directly connected before the intervention. The second was to establish the most appropriate anti-seismic technology in the construction systems and the third was to generate a design concept that incorporates the above-mentioned issues into a workable solution. Conducting this brief evaluation on the completed batch of the core housing project of MERCY enabled us to rectify future shortcomings and to improve relief efforts succinctly to a particular locality.
\end{abstract}

Keywords: disaster, humanity, community, social and cultural impact, temporary shelter, anti-seismic, low technology, rehabilitation, reconstruction.

\section{Introduction}

A sudden change in the life of tsunami survivors in Aceh (Fig. 1) has forced NGOs and particularly architects to come up with ideas that would help reorganize and redirect their lives towards the norm of humanity. Suddenly 
architecture was all about saving human lives. The appalling condition under which the Internally Displaced Person (IDP) ekes out a meager existence was only too well known. IDPs occupy dilapidated properties that had survived the tsunami. As the absorbing capacity of these areas reached saturation, IDPs were forced to squat on whatever land that was available. As the IDP population increased, sections of them were forced to occupy even the most undesirable places that one could imagine.

The forcible relocation of IDPs into barracks inevitably generated social tension. In isolated instances, NGOs and authorities were compelled to recognize the tenancy rights of IDPs after nearly all means to avoid confrontation, jealousy and social illness have been exhausted [1]. However, these cases are only shortterm solutions. Relief works and interventions should seek to reinstate the basic needs of human existence. It was our belief and obligation that a sustainable community planning could provide the framework for the fulfillment of these basic human needs. This belief underpins our approach in providing basic shelter to the victims: mobilizing creative and innovative thinking and technology in safeguarding their future survival on this devastated land.
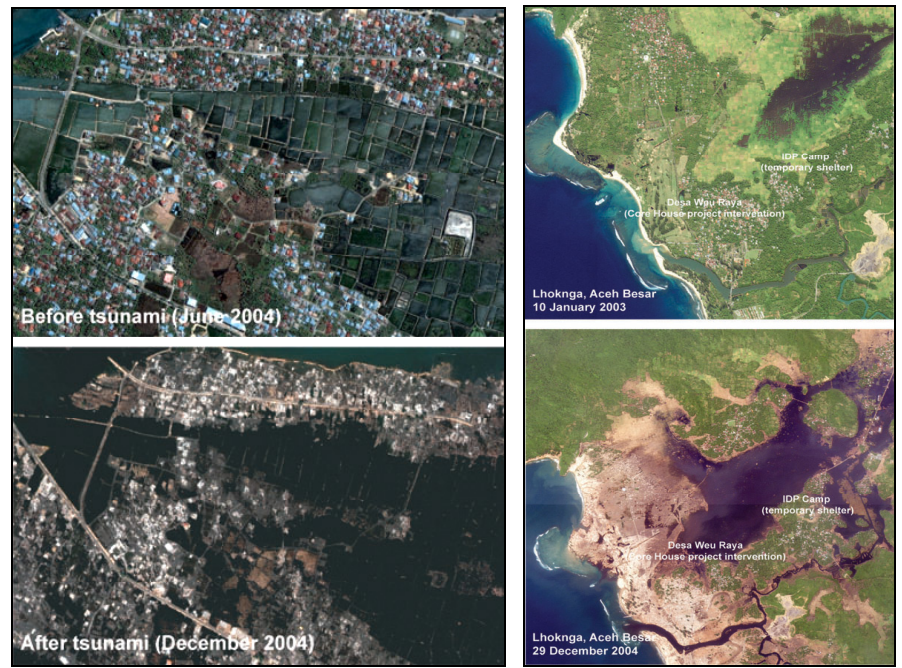

Figure 1: Banda Aceh and Aceh Besar, before and after tsunami. Courtesy of United Nations Humanitarian Information Center (HIC).

Even as the first relief supplies were being delivered to locations in Aceh, MERCY Malaysia was responding to the emerging long-term needs of the Acehnese people, signing a Service Level Agreement (SLA) letter with the local government to build Core Houses while adopting a whole village in the weeks after the tsunami. The nature of the project will be a redevelopment of a village at Desa Weu Raya, situated one kilometer from the hardest hit coastline of Aceh. The master plan includes a rebuilding proposal to replace 231 units of core houses for the remaining families of the village of Desa Weu Raya, which used to be the homes for more than 3000 lives, now only hosting 600 survivors. The 
proposal (Fig. 2) was a module of $52 \mathrm{~m}^{2}$ single storey seismic resistant, semi brick core house with flexibility to be expanded upon future needs, consisting of two bedrooms, a living room and a front and a rear terrace. These terraces may be converted into kitchen, additional bedroom, or to be expanded to the size of the housing unit. Communal toilet facilities were built as requested by the villagers.

\section{The approaches}

Even before the tsunami, millions of people in the affected areas were living in conditions of poverty unimaginable to most people. In Aceh, the security of lives, possessions, and infrastructure have been threatened by several years of armed conflict. According to the government's own statistics [2], in 2002, nearly 48.5 percent of the population had no access to clean water, 36.2 percent of children under the age of five were undernourished, and 38 percent of the population had no access to health facilities. The poverty rate doubled from 14.7 percent in 1999 to 29.8 percent in 2002. These problems worsened with the recurring yearly disaster that struck Indonesia.

Due to these disturbing statistics, three main issues were carefully considered in the development of a critical praxis around a disaster-hit area. First was to identify ways to approach community needs, social and cultural understanding, and economic factors, which were profoundly connected prior to the interventions. The second issue was to devise anti-seismic systems of constructions. The third issue was to establish design concepts derived from the two mentioned issues, which were then translated into workable solutions. Before rebuilding works could be executed the remaining 600 villagers were relocated temporarily into IDP camps.

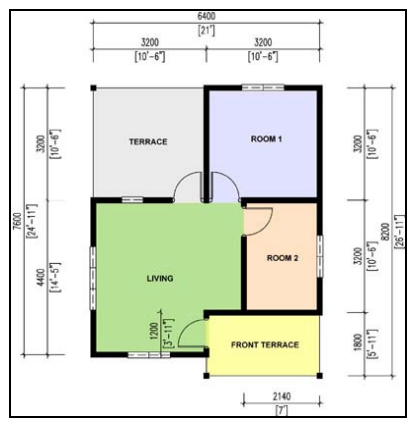

Figure 2: Core House plan.

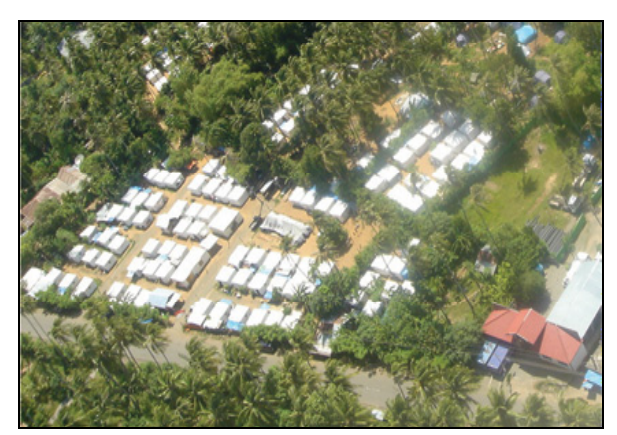

Figure 3: Desa Weu Raya IDP Camp.

A tent village (Fig. 3) to host the families temporarily for six months was constructed while waiting for the Core Houses to be completed. 231 tents were erected on a vacant land donated by one of the tsunami victims. The tent village also included community spaces such as a praying area, mobile clinics, spacious toilet facilities, a kindergarten, an activity area for children and women, office space for the village administration and tents that can be used as shops to help 
rebuild the social and economic capacity of the victims. The tents, fabricated of lightweight and durable materials (Fig. 4) were easily assembled (no skill workers required) with minimal logistic requirements. The villagers of Desa Weu Raya managed comfortably in this tent village while waiting for the new houses to be completed (Fig. 5).

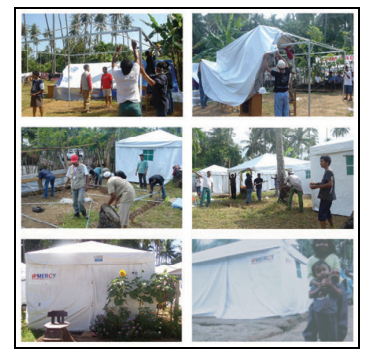

Figure 4: Setting up a tent village.

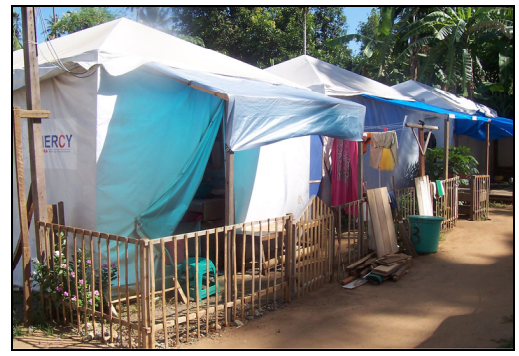

Figure 5: The IDP camp setting.

\subsection{Community needs, social and cultural understanding, and economic factors}

In general, there are two types of architecture. The first responds to contextual needs and the other driven by market forces. Disaster has taught architects to work like Hassan Fathy [3] who propagated the incorporation of considerations for social-cultural and local components of the built form in the design process. In addition, informal discussions and regular visits to the IDP camp have molded MERCY's understanding of the community needs. The theory of 'small is beautiful' and the concept of self-help approaches to shelter should be accorded greater emphasis.

In general post-disaster settlement must be constructed of permanent structures with the necessary infrastructural facilities and amenities [4]. The World Bank, the United Nations and many other experts have concluded that tsunami-hit areas like Aceh would need billions of dollars of external assistance to finance their basic shelter needs. As this aid is constantly available, but not efficiently distributed, thousands of tsunami survivors are still condemned to live in sub-standard living environments.

The complex relationship between the architect and the community must be established before any interventions can take place. In this project, the feasibility of the interventions, which included availability of materials, work force and construction techniques, had been carefully scrutinized before any final decisions were made, In coordination meetings, agreements were only achieved after both parties had fully understood the reality of the life faced by tsunami victims and the architect's aim. What emerged from these understandings was then put to test by constructing them.

\subsection{Anti seismic technology in building construction}

In lieu of human losses in recent earthquakes and tsunamis, not much research and development were conducted on seismic resistance of low-cost masonry and 
timber buildings [5]. Research centres and universities of the developed and developing countries have carried out extensive amount of earthquake related research and development but these deal mainly with expensive modern buildings.

Due to economic and contextual constraints in post-tsunami Aceh, only masonry and timber houses were the best choice for MERCY Malaysia to construct for the IDPs. This type of construction cannot be replaced quickly and easily with modern earthquake resistant construction systems due to the large dependence on low technology, availability of material and local workforce.

Unreinforced masonry and timber structures generally have a brittle lateralload-resisting system. These types of buildings have poor seismic performance. Total or partial collapse of these structures has been one of the main causes of the loss of life during past earthquakes [6] (Fig. 6). Some of the important causes of the failure of the walls and the subsequent collapse of roofs of this type of structure are as follows:

1 The low durability and the poor strength of materials (earth/clay) used in the construction of adobe buildings.

2 The inferior quality of the mortar used in the construction of bricks, concrete blocks or masonry buildings.

3 Lack of sufficiently strong connection between the various elements of the structure, such as between walls, partitions and roof. In addition, the brittleness and low strength of the individual elements especially the walls. Often, these structures do not behave as a rigid frame. Under moderate shaking, various elements become disconnected from each other and gradually causing the failure of the whole system.

4 The collapse of the unreinforced load-bearing walls, partitions and spandrels over the openings due to the effects of shear-compression and shear-tension. The failure modes by these effects are very brittle and highly strength degrading. Therefore, under intense tremor, the wall elements crack and subsequently disintegrate the load-bearing walls and partitions, destroying the lateral strength and rigidity of the structure and also the vertical-load carrying capacity of the walls, resulting in the collapse of roofs and supporting structures.

5 Disintegration of the heavy, brittle, non-monolithic and non-rigid timbered roofs or roofs made of unbraced trusses.
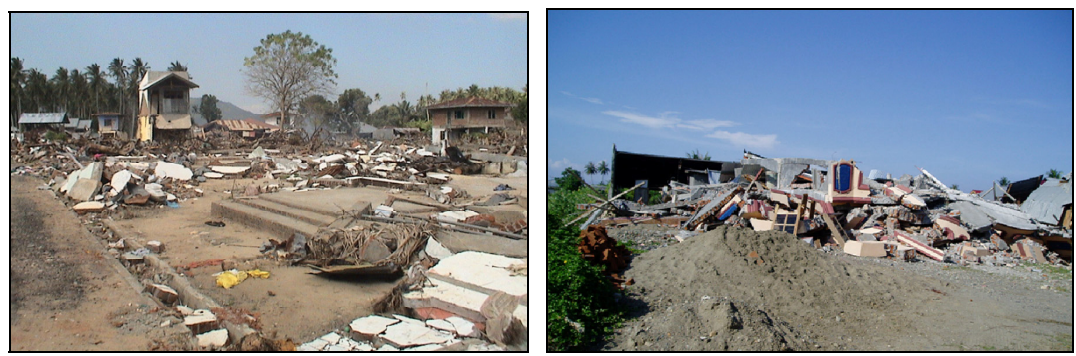

Figure 6: $\quad$ Poor seismic performance of domestic buildings in Aceh. 
Due to time constraints and shortage of skilled workers, materials, machineries, and capital, MERCY Malaysia's first batch of core houses for the IDPs were constructed without complicated earthquake resistant design. Instead an alternative technique in preventing the collapse of the roof and other structure of houses was used. This technique was developed by MERCY Malaysia in collaboration with other experts. The technique incorporates a simple braced skeleton system (Fig. 7) within the house design that can prevent structure failure and collapse during an earthquake [7]. The function of this skeleton is to tie together various parts of the building. The main design components of this system are:

1 A horizontal in-plane diagonal bracing system to tie together the roof beams so that a monolithic roof with sufficient rigidity is obtained (Fig. 8).

2 An auxiliary system of timber or reinforced concrete columns embedded within the masonry walls so that in case of destruction of the walls, the ductile columns can support the vertical loading.

3 These columns are braced together laterally by means of a vertical system of diagonal bracing in such a way that the lateral instability and subsequent collapse of the structure during earthquake is prevented (Fig. 9).

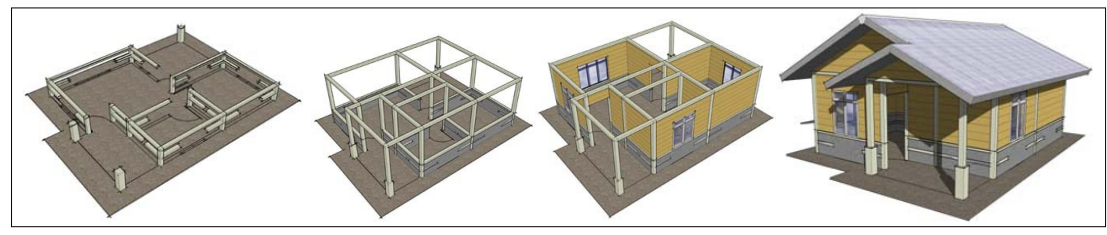

Figure 7: Construction concept and techniques.

In reference to the proposed earthquake protection criteria for the Core Houses, the primary goal is to prevent structural collapse during major earthquakes. From our research and experiments through earthquake simulations (Fig. 10), a structure become less susceptible to collapse under strong earthquake if:

1 The roof and floor of the building remain monolithic with sufficient in-plane rigidity during and after earthquakes;

2 The vertical load-carrying system of the structure can survive the earthquake without impairment to its function;

3 The lateral load-resisting system of that structure during the main earthquake and succeeding after shocks can retain enough residual capacity to resist safely the lateral forces due to lateral instability, wind load and future earthquake lateral loads.

Collaborations between architects, engineers, contractors, experts, humanitarians and local communities have resulted in an idea of tolerance that reduces the risk of construction failure during earthquakes. Without overestimating the omnipotence of new construction method and technology, architects should remain committed to utilizing the progressive potentials of surrounding resources. A limited budget, shortage of materials, machineries, and 
skilled workers had driven the architects to undertake creative solutions. The architects are inherently charged with the mission of creating designs that contribute towards the enhancement of the victims' quality of life. The use of technology and techniques should always be constructive to civilization. Technology must be manageable by the locals for their benefit. MERCY Malaysia has collaborated with local and foreign experts from Kyoto University, Japan, Universitas Syiah Kuala, Banda Aceh (UNSYIAH), National Society for Earthquake Technology, Nepal (NSET), Geo Hazards International (GHI) and contractors in the conceptualization and realization of the Core House project.
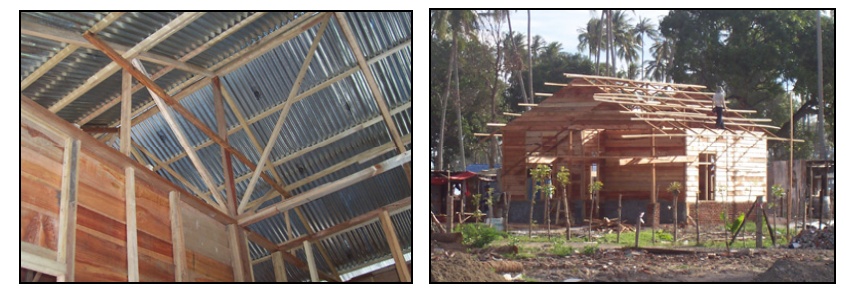

Figure 8: $\quad$ Roof bracing to obtain sufficient rigidity.
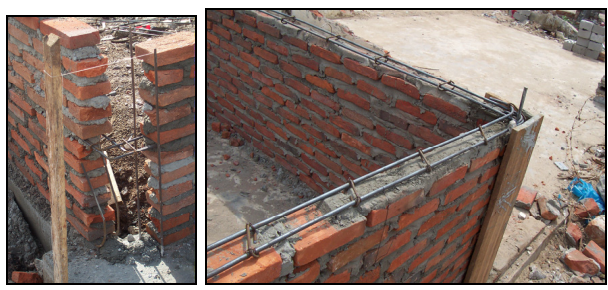

Figure 9: Diagonal bracing to prevent lateral instability.
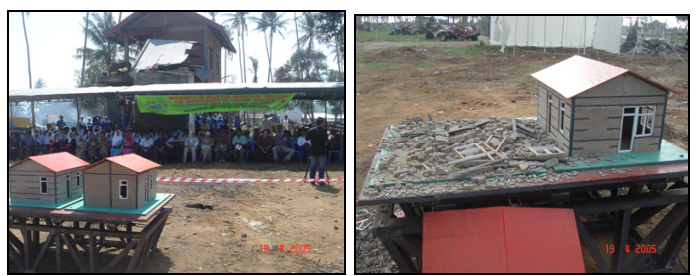

Figure 10: Shake table earthquake simulation to test the idea of seismic resistant design and construction.

The development of anti-seismic construction methods and techniques has been channeled down to the local community and authorities through workshops, simulations, presentations and discussions. During these stages, MERCY progressively learned to appreciate the contextual components of the area (soil, climate, availability of resources, etc.). It was also important to understand the construction techniques practiced by Aceh builders in order to introduce them to alternative and better techniques. As architecture is gradually absorbed into the knowledge industry, and the role of the architect has shifted from building to 
organizing social relations, MERCY Malaysia feels that in any future interventions of the public realms, a better inter-relation between the architects and the end users must be established in order to generate successful aid programmes [8].

\section{Implementation concepts}

After three months of preparatory work, the proposed Core House scheme for the devastated conurbation started in March 2005 and was successfully completed within six months. This was possible because the programme did not adhere to the static land use requirements and blue prints prepared by the local Shelter Working Group and the Reconstruction and Rehabilitation Body (BRR), which, are so frequently produced but regularly shelved or unexecuted. The deficiencies of the blue print, as well as the constraints imposed by the regional condition were clearly set out in the scheme. The scheme as a whole was an indicative, policy-oriented proposal rather than a definitive housing scheme based on statutory rules, space requirements and other essentially concerns with political decision-making and implementation. The notion of dichotomy between capacity building and social restructuring, which was unrelated to the resource of allocation has been put aside.

With respect to the daily living conditions in Aceh, the major physical deficiencies identified in our studies are the most elemental: adequate and safe shelter and the sub-standard living environments for the foreseeable future. The maximum elevation within the district is only about two meters above mean sea level and the area has little clean water supply. Most of the lands were swept by seawater. The ground spaces in these settlements must be fully and expansively utilized. The absence of trees had caused the area to be susceptible to strong winds and the possibility of another tidal encroachment. There is no proper sewerage system around the remaining land. The vast majority of the people depend on service privies; a small shed containing a seating platform with earthenware bowl underneath for the disposal of excreta.

MERCY Malaysia Core House scheme outlined a desperate position in respect of critical shelter need. The sheer inadequacy and constant deterioration in living condition in the fullest environmental and social senses are central to a broad range of Aceh's current problems, and the plan fully acknowledges our commitment to provide shelter and to improve living conditions in both the short- (IDP Camp settlements) and the long-term (Core House) perspectives (Fig. 11). There are unique strains on working with the community in several parts of the tsunami-hit areas. In some places where a substantial number of affected people we encountered were still holding on to strong principles of traditional ways of lifestyles. As such, MERCY Malaysia and its partners had to find roles in advising and educating them on the best practices of disaster preparedness and safe construction. From previous experiences, we try to ensure that the voices of tsunami-affected people are heard by having:

1 Bi-weekly meetings with villagers, community leaders, religious leaders, authorities and other NGOs, discussing issues of spatial ordering, various 
post-disaster management initiatives, and issues related to reconstruction and rehabilitation.

2 On site discussions with each beneficiary (house owner) in determining their own plot of land, house positioning, boundaries, nearest escape routes, and to make sure all beneficiaries are well informed on the designated mitigation plans, safe areas, escape routes, disaster management zones and ways of alerting each other.

3 Effective disaster mitigation that focuses on the key elements of self-help, cooperation and education through activities such as: (a) research projects; (b) training and capacity building; (c) a series of international workshops, and (d) advisory services.

4 Discussions that lead to a development of prevention and mitigation plans. From the plans, we have produced a comprehensive escape routes plan for the village of Desa Weu Raya, designed clear signage and iconographic symbols that lead to the escape routes, and have made clear guidelines on what should be done whenever disaster alert information is being disseminated and made known before, during, and after a disaster.
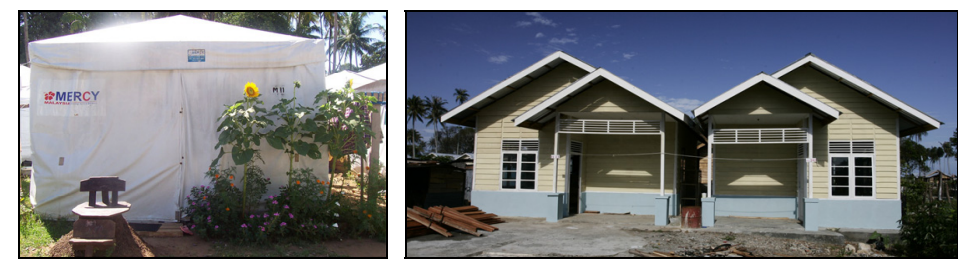

Figure 11: IDP Camp settlements and the completed Core House.

\section{Conclusion}

In building houses for a community that live with risks, all plans that have been developed need to be properly studied, discussed, and put to test. All plans applied must be re- analyzed to ensure its effectiveness and workability in responding to a wider global context. Tests have to be done in a practical manner by organizing workshops, forums, simulations, trainings and networking with other inter-related agencies. Public participation is a must to fully understand the needs and in responding to these needs. An overall review on the systems and plans will produce new improvised results, which will help in producing a wellprepared action plan in disaster and other acute cases. The tested idea must be well documented and to be spread to a wider audience of humanitarian workers, experts in the built environment, and the civil society [9].

The intention of this project is not so much a complete 'otherness' from other ad-hoc disaster related housing development, but rather a symbiotic merging with its context. Permeable boundaries allow extensions inwards and outwards, and encourage inhabitants to convene, converge, and enjoy the many possibilities offered within the new reconstruction development. This posttsunami planning substance that connects and separates, is amorphous, fluid, organic, and can contain within itself as well as surround (the other). 
Floating within this idea, the Core Houses allow for differences and pronounced simultaneities to grow and mutate but balanced act in the desperate condition of the inhabitants. Their containment allows further expansions. The beneficiaries will find their ideal position within the site by almost naturally gravitating towards desirable adjacencies: family needs, economic conditions, similarities to surrounding typologies, ideal community connections, neighboring activities, or just the most basic shelter provided. It is an amalgam of family togetherness and societies' strength. It is, in essence, architecture for humanity (Fig. 12).

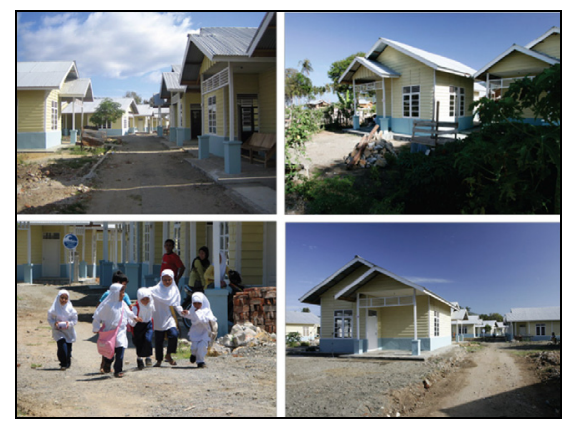

Figure 12: Core House Desa Weu Raya, Lhoknga, Aceh, Indonesia.

\section{References}

[1] Morris, Eric, UN Recovery coordinator for Aceh. 'A Place to Stay, A Place to Live', Challenges in Providing Shelter in India, Indonesia and Sri Lanka after the Tsunami, Oxfam International: London, 2005.

[2] Indonesian Human Development Report 2004, The Economics of Democracy: Financing Human Development in Indonesia', BPS-Statistics Indonesia, BAPPENAS and UNDP: Indonesia, 2004.

[3] Fathy, Hassan, Architecture for the Poor: An Experiment in Rural Egypt, University of Chicago Press: Chicago, 1973.

[4] Pendick, D., Build Smart Not Hard, State University of New York, Courtesy of www.labdna.com: New York, 2004.

[5] Razani R., Criteria for Seismic Design of Low Cost Housing, Pergamon Press, The East West Center: New York, 1979.

[6] Goodman, L.J. \& Tabujara, E.G., (eds). Low-Cost Housing Technology, an East-West Perspective, Pergamon Press, The East West Center: New York, 1979.

[7] Samah, N.A., Safe Building in Disaster Area (Unpublished Master Thesis), Department of Engineering, Faculty of Engineering, Universiti Sains Malaysia: Malaysia, 2006.

[8] Mahmood, J., MERCY Malaysia Annual Report 2005, www.mercy.org.my

[9] Amirrol, H. \& Samah, N.A., Civil Society Role in Disaster; Disaster Risk Reduction: Learning From Tsunami Experience Training Workshop, MERCY Malaysia: Kuala Lumpur, 2006. 